\title{
Retinal pigment epithelial tears after intravitreal bevacizumab injection for exudative age-related macular degeneration.
}

\author{
Sunir Garg \\ Thomas Jefferson University \\ Roy Brod \\ Roy Brod \\ David Kim \\ Wilford Hall Medical Center \\ R Gary Lane \\ Wilford Hall Medical Center \\ Joseph Maguire \\ Thomas Jefferson University
}

Follow this and additional works at: https://jdc.jefferson.edu/willsfp See next page for additional authors

Part of the Medicine and Health Sciences Commons

Let us know how access to this document benefits you

\section{Recommended Citation}

This article has been peer reviewed. It is the authors' final version prior to publication in Clinical and Experimental Ophthalmology Volume 36, Issue 3, April 2008, Pages 252-256. The published version is available at . DOI: 10.1111/j.1442-9071.2008.01710.x. Copyright @ Wiley Interscience.

This Article is brought to you for free and open access by the Jefferson Digital Commons. The Jefferson Digital Commons is a service of Thomas Jefferson University's Center for Teaching and Learning (CTL). The Commons is a showcase for Jefferson books and journals, peer-reviewed scholarly publications, unique historical collections from the University archives, and teaching tools. The Jefferson Digital Commons allows researchers and interested readers anywhere in the world to learn about and keep up to date with Jefferson scholarship. This article has been accepted for inclusion in Wills Eye Hospital Papers by an authorized administrator of the Jefferson Digital Commons. For more information, please contact: JeffersonDigitalCommons@jefferson.edu. 


\section{Authors}

Sunir Garg, Roy Brod, David Kim, R Gary Lane, Joseph Maguire, and David Fischer 
As submitted to: Clinical and Experimental Ophthalmology and later accepted for publication as:

"Retinal pigment epithelial tears after intravitreal bevacizumab injection for exudative age-related macular degeneration"

Clinical and Experimental Ophthalmology

Volume 36, Issue 3, April 2008, Pages 252-256

DOI: 10.1111/j.1442-9071.2008.01710.x

\section{Original Article - Clinical Science}

Retinal pigment epithelial tears after intravitreal bevacizumab injection for exudative age-related macular degeneration

Sunir Garg, MD ${ }^{1}$, Roy Brod, $\mathrm{MD}^{2}$, David Kim, MD³ , R. Gary Lane, $\mathrm{MD}^{3}$, Joseph Maguire, $\mathrm{MD}^{1}$, David Fischer, $\mathrm{MD}^{1}$

${ }^{1}$ The Retina Service of Wills Eye Institute, Thomas Jefferson University, Philadelphia, PA; ${ }^{2}$ Roy Brod, Lancaster, PA; ${ }^{3}$ Wilford Hall Medical Center, San Antonio, TX

Corresponding author:

Sunir J. Garg, MD

The Retina Service of Wills Eye Institute Assistant Professor of Ophthalmology

Thomas Jefferson University 
840 Walnut Street, Suite 1020

Philadelphia, PA 19107

Office: (610) 649-1970

Fax: (610) 649-8624

sunirgarg@yahoo.com

Running title: RPE tears after intravitreal bevacizumab

Financial support: None

No conflicting relationship exists for any author. 


\begin{abstract}
Purpose: To determine the incidence of and the risk factors for the development of retinal pigment epithelial (RPE) tears after intravitreal bevacizumab (Avastin) injection for the treatment of exudative age-related macular degeneration (AMD).

Methods: A retrospective, multicenter, consecutive interventional case series of all patients with subfoveal exudative AMD treated with intravitreal bevacizumab between August 2005 and April 2007. The main outcome measures were pre- and post-RPE tear visual acuity and choroidal neovascular membrane lesion types, incidence of tears, and time from first injection until development of the tear.

Results: A total of 920 eyes with exudative AMD were treated with intravitreal bevacizumab. 15 eyes from 15 patients developed a RPE tear for an incidence of $1.6 \%$. The average patient age was 79 years. 14/15 eyes (93\%) had an occult subfoveal choroidal neovascular membrane. 47\% (7/15) of the RPE tears occurred within the first 6 weeks of treatment, and all tears occurred within the first 18 weeks of treatment initiation. The mean pre-injection visual acuity was $20 / 100$ with a mean post tear visual acuity of 20/200. In all ten eyes in which the tear involved the fovea, the final visual acuity was poor. Six of the 15 eyes continued with bevacizumab/ ranibizumab (Lucentis) injections after tear development, and four of these six eyes continued to have visual improvement.
\end{abstract}

Conclusion: RPE tears occur after intravitreal bevacizumab injections for exudative AMD in approximately $1.6 \%$ of eyes and can cause severe vision loss. Maintenance of therapy may help preserve vision after RPE tear development.

Keywords: bevacizumab, Avastin, retinal pigment epithelium, macular degeneration, tear 
RPE tears after intravitreal bevacizumab injections

Introduction

Tears of the retinal pigment epithelium (RPE) may occur spontaneously as part of the natural history of exudative age-related macular degeneration (AMD) ${ }^{1,2}$. They have also been reported after treatment for exudative AMD, including thermal laser photocoagulation and photodynamic therapy $(\mathrm{PDT})^{3-6}$. There have been reports of RPE tears after intravitreal injection of anti-vascular endothelial growth factor (VEGF) agents, including pegaptanib sodium (Macugen), ranibizumab (Lucentis) and bevacizumab (Avastin) ${ }^{7-17}$.

Bevacizumab (Avastin ${ }^{\circledR}$; Genentech, South San Francisco, CA) is a recombinant humanized monoclonal antibody that binds VEGF and inhibits its interaction with receptors found on endothelial cells. It has been used increasingly as an off-label treatment for exudative AMD, but without long-term, randomized controlled trials examining safety and efficacy ${ }^{18-20}$. It has been hypothesized that intravitreal bevacizumab causes contraction of choroidal neovascular membranes, thus accelerating RPE tear development $^{11}$.

The purpose of this study is to report the incidence of and risk factors for the development of retinal pigment epithelial (RPE) tears after intravitreal bevacizumab (Avastin) injection for the treatment of exudative AMD.

\section{Methods}

After institutional review board approval was obtained, a retrospective review of all patients treated with intravitreal bevacizumab for subfoveal exudative AMD between August 2005 and April 2007 by the investigators was performed (The Retina Service of Wills Eye Institute, Philadelphia, PA; Roy Brod, LLC, Lancaster, PA; and Wilford Hall Medical Center, San Antonio, TX). Eyes were included if they developed a RPE tear after initiation of intravitreal bevacizumab therapy. These patients may have had treatment with thermal laser, photodynamic therapy or pegaptanib sodium prior to injection of bevacizumab, however, once intravitreal bevacizumab treatment was initiated, at least three injections were performed before adjuvant therapy (for example PDT or intravitreal triamcinolone) was added, or before the patient was switched to ranibizumab (Lucentis, Genentech, South San Francisco, CA). Patients were excluded if they received intravitreal ranibizumab prior to RPE tear occurrence or if the status of the RPE could not be assessed prior to initiation of treatment (for example, due to a thick submacular hemorrhage). Baseline fluorescein angiography (FA) was obtained on all patients. Baseline optical coherence tomography (OCT) was obtained at the discretion of the investigator. Follow up examinations were performed at approximately six-week intervals. Patients were identified with an RPE tear based on clinical examination and OCT and/or fluorescein angiography as needed. After discovery of the tear, additional treatment was performed at the discretion of the investigator.

The procedure for intravitreal injection of bevacizumab is briefly as follows. After informed consent was obtained, the eye was prepped using topical anesthesia and 
RPE tears after intravitreal bevacizumab injections

$5 \%$ povidone-iodine. A lid speculum was placed, and $1.25 \mathrm{mg}(0.05 \mathrm{ml})$ of bevacizumab was injected through the pars plana approximately $3.5 \mathrm{~mm}$ to $4 \mathrm{~mm}$ from the surgical limbus using a 30-gauge needle. Post-operatively, the patients were instructed to use a topical antibiotic at the discretion of the investigator. The patient returned approximately 6 weeks later for a follow up examination.

On follow up, the primary outcome measure was Snellen visual acuity. Snellen visual acuity was converted to the logarithm of the minimal angle of resolution (LogMAR) for data interpretation. Data was recorded for patient age, gender, eye involved, baseline vision, baseline lesion type, follow up visual acuities, number of treatments, date of the RPE tear occurrence, and subsequent treatments, if any. Any ocular or systemic adverse events were also recorded.

\section{Selected Case Reports}

Results

A total of 920 eyes that received a total of 3339 intravitreal injections of bevacizumab were identified from the practices of the investigators during the study period. A total of 15 eyes from 15 patients with post-injection tears of the RPE were found (Table 1). The mean patient age was 79 years (range, 66-93 years) and all patients were Caucasian. Five patients were males and 10 patients were female. 10 cases involved the left eye. 14 eyes never had previous treatment for exudative AMD in the study eye. One patient had received 7 pegaptanib sodium (Macugen) injections prior to the first bevacizumab injection. The mean follow up period was 26 weeks (range, 12-52 weeks).

14 patients had an occult subfoveal choroidal neovascular membrane. One patient had a minimally classic membrane. No patient had a classic membrane. Four of the 15 eyes had a serous pigment epithelial detachment at baseline examination. The average size of the neovascular lesion was $10.31 \mathrm{~mm}^{2} \pm 12.21 \mathrm{~mm}^{2}$.

Seven of the 15 RPE tears occurred after the first bevacizumab injection; six of the 15 occurred after the second injection, and two of 15 occurred after the third injection.

Baseline median visual acuity was $20 / 60$ and mean visual acuity was $20 / 100$ (range, 20/25-3/200). After occurrence of the tear, the median visual acuity was 20/140, and mean visual acuity was 20/200 (range, 20/30-3/200). At last follow up, the median visual acuity was 20/100, and the mean visual acuity was 20/200 (range, 20/25-3/200). At the discretion of the investigator, six of the 15 eyes received additional bevacizumab or ranibizumab injections after development of the RPE tear. The mean baseline visual acuity of these eyes was 20/100 (range, 20/40-3/200). Immediately after the tear, the mean visual acuity was 20/100 (range, 20/50-20/200), and mean visual acuity at last follow up was 20/160 (range 20/25-3/200).

Discussion 
Off-label intravitreal injection of bevacizumab is used to treat a number of ocular conditions, including proliferative diabetic retinopathy, diabetic macular edema, retinal vein obstructions, neovascular glaucoma, and choroidal neovascular membranes due to myopia and age-related macular degeneration ${ }^{21-27}$. Although seemingly well tolerated and efficacious for the treatment of exudative AMD, intravitreal bevacizumab has been associated with tears of the retinal pigment epithelium in several case reports as well as in recent, larger case series ${ }^{8-11,15-17}$.

We report a $1.6 \%$ incidence of RPE tears in association with intravitreal bevacizumab injections. Furthermore, nearly half of these cases occurred after the first bevacizumab injection (7/15) and all occurred within 18 weeks of starting treatment. Chan and colleagues found that $73 \%$ of the RPE tears occurred after the first injection. This may be due to the fact that $8 / 22$ of their patients were treated with $2.5 \mathrm{mg}$ of bevacizumab in contrast to the $1.25 \mathrm{mg}$ dose used for our patients. In their paper, $2.6 \%$ of patients that received $2.5 \mathrm{mg}$ of bevacizumab developed a RPE tear, versus $2.2 \%$ of patients in the $1.25 \mathrm{mg}$ group. This difference, however, was not statistically significant. Additionally, $7 / 22$ eyes in their study versus only $1 / 15$ eyes in our study received prior treatment for exudative AMD. This may have predisposed some eyes to RPE tear development. In this series, 14/15 RPE tears were seen in occult neovascular AMD. In contrast to the study by Ronan and colleagues, only $27 \%(4 / 15)$ in our study had a significant serous pigment epithelial detachment (PED) ${ }^{16}$. None of these tears occurred in eyes with a classic choroidal neovascular membrane, but as only $10 \%$ of exudative AMD have classic membranes, this result may simply reflect the relative incidence of choroidal neovascular types and not risk for RPE tear development. No significant systemic or ocular side effects were evident.

Overall, after occurrence of the RPE tear, most patients experienced significant visual loss. However, in eyes in which the tear spared the fovea, the visual results could be good and there could even be visual improvement. Six eyes continued to receive intravitreal injection of ranibizumab or bevacizumab after RPE tear development; in four of these six eyes vision continued to improve, supporting maintenance of therapy as suggested by Chan et $\mathrm{al}^{15}$. There were no consistent findings to help determine which eyes would benefit from continued treatment after RPE tear development, however continued treatment with an anti-VEGF agent should be considered in patients in whom the RPE tear spares some or all of the fovea or in whom the vision is still subjectively good.

Tears of the RPE have been reported as part of the natural history of AMD, as well as after thermal laser, photodynamic therapy, intravitreal pegaptanib sodium, ranibizumab and bevacizumab injections. Although the ANCHOR and MARINA studies reported no cases of RPE tears with ranibizumab (from a total of 758 eyes), there have been anecdotal reports of its occurence ${ }^{12,14,28,29}$. In the photodynamic therapy trials with Visudyne (Novartis) (TAP and VIP studies) the incidence of RPE tears was not commented upon $^{30,31}$. A recent report found a 13\% incidence RPE tears after photodynamic therapy with verteporfin for choroidal neovascular membrane associated with pigment epithelial detachment ${ }^{32}$.

This report is limited because it is a retrospective study with no control group. It is possible that other patients had small or otherwise undetected RPE tears. If other patients had RPE tears that were missed, the incidence of tears of the RPE could be 
higher than reported here. Patients started on bevacizumab and then switched to ranibizumab after their first intravitreal injection were excluded from analysis which could also cause underestimation of the risk.

In conclusion, this study demonstrates a $1.6 \%$ incidence of RPE tears after intravitreal injection of bevacizumab, which is higher than that seen in the randomized controlled trials with ranibizumab or Visudyne. Patients should be counseled that RPE tears may occur as a consequence of bevacizumab therapy, but may be simply part of the underlying disease process. Patients with occult choroidal neovascular membranes and those with a large serous PED may be at higher risk of developing this complication and should be counseled appropriately. Clinicians should also be aware that some patients benefit from continued treatment with an anti-VEGF agent even after development of the tear. Larger randomized, controlled clinical studies with long-term follow-up will be necessary to further establish whether intravitreal bevacizumab injection increases the incidence of RPE tears in eyes with exudative AMD.

1. Hoskin A, Bird AC, Sehmi K. Tears of detached retinal pigment epithelium. Br J Ophthalmol 1981;65(6):417-22.

2. Gass JD. Pathogenesis of tears of the retinal pigment epithelium. Br J Ophthalmol 1984;68(8):513-9.

3. Decker WL, Sanborn GE, Ridley M, et al. Retinal pigment epithelial tears. Ophthalmology 1983;90(5):507-12.

4. Gass JD. Retinal pigment epithelial rip during krypton red laser photocoagulation. Am J Ophthalmol 1984;98(6):700-6.

5. Pece A, Introini U, Bottoni F, Brancato R. Acute retinal pigment epithelial tear after photodynamic therapy. Retina 2001;21(6):661-5.

6. Gelisken F, Inhoffen W, Partsch M, et al. Retinal pigment epithelial tear after photodynamic therapy for choroidal neovascularization. Am J Ophthalmol 2001;131(4):518-20.

7. Dhalla MS, Blinder KJ, Tewari A, et al. Retinal pigment epithelial tear following intravitreal pegaptanib sodium. Am J Ophthalmol 2006;141(4):752-4.

8. Nicolo M, Ghiglione D, Calabria G. Retinal pigment epithelial tear following intravitreal injection of bevacizumab (Avastin). Eur J Ophthalmol 2006;16(5):770-3.

9. Gelisken F, Ziemssen F, Voelker M, Bartz-Schmidt KU. Retinal pigment epithelial tear following intravitreal bevacizumab injection for neovascular age-related macular degeneration. Acta Ophthalmol Scand 2006;84(6):833-4.

10. Spandau UH, Jonas JB. Retinal pigment epithelium tear after intravitreal bevacizumab for exudative age-related macular degeneration. Am J Ophthalmol 2006;142(6):1068-70.

11. Shah CP, Hsu J, Garg SJ, et al. Retinal pigment epithelial tear after intravitreal bevacizumab injection. Am J Ophthalmol 2006;142(6):1070-2.

12. Rosenfeld PJ, Brown DM, Heier JS, et al. Ranibizumab for neovascular agerelated macular degeneration. N Engl J Med 2006;355(14):1419-31.

13. Apte RS. Retinal pigment epithelial tear after intravitreal ranibizumab for subfoveal CNV secondary to AMD. Int Ophthalmol 2007;27(1):59-61. 
RPE tears after intravitreal bevacizumab injections

14. Brown DM, Kaiser PK, Michels M, et al. Ranibizumab versus verteporfin for neovascular age-related macular degeneration. N Engl J Med 2006;355(14):1432-44.

15. Chan CK, Meyer CH, Gross JG, et al. Retinal Pigment Epithelial Tears after

Intravitreal Bevacizumab Injection for Neovascular Age-Related Macular Degeneration. Retina 2007;27(5):541-51.

16. Ronan SM, Yoganathan P, Chien FY, et al. Retinal Pigment Epithelium Tears after Intravitreal Injection of Bevacizumab (Avastin) for Neovascular Age-Related Macular Degeneration. Retina 2007;27(5):535-40.

17. Chang LK, Sarraf D. TEARS OF THE RETINAL PIGMENT EPITHELIUM: An Old Problem in a New Era. Retina 2007;27(5):523-34.

18. Rosenfeld PJ, Moshfeghi AA, Puliafito CA. Optical coherence tomography findings after an intravitreal injection of bevacizumab (avastin) for neovascular agerelated macular degeneration. Ophthalmic Surg Lasers Imaging 2005;36(4):331-5. 19. Bashshur ZF, Bazarbachi A, Schakal A, et al. Intravitreal bevacizumab for the management of choroidal neovascularization in age-related macular degeneration. Am J Ophthalmol 2006;142(1):1-9.

20. Avery RL, Pieramici DJ, Rabena MD, et al. Intravitreal bevacizumab (Avastin) for neovascular age-related macular degeneration. Ophthalmology 2006;113(3):363-72 e5.

21. Ahmadieh H, Moradian S, Malihi M. Rapid regression of extensive retinovitreal neovascularization secondary to branch retinal vein occlusion after a single intravitreal injection of bevacizumab. Int Ophthalmol 2005;26(4-5):191-3.

22. Haritoglou C, Kook D, Neubauer A, et al. Intravitreal bevacizumab (Avastin) therapy for persistent diffuse diabetic macular edema. Retina 2006;26(9):999-1005.

23. Isaacs TW, Barry C. Rapid resolution of severe disc new vessels in proliferative diabetic retinopathy following a single intravitreal injection of bevacizumab (Avastin). Clin Experiment Ophthalmol 2006;34(8):802-3.

24. Oshima Y, Sakaguchi H, Gomi F, Tano Y. Regression of iris neovascularization after intravitreal injection of bevacizumab in patients with proliferative diabetic retinopathy. Am J Ophthalmol 2006;142(1):155-8.

25. Avery RL. Regression of retinal and iris neovascularization after intravitreal bevacizumab (Avastin) treatment. Retina 2006;26(3):352-4.

26. Tewari A, Dhalla MS, Apte RS. Intravitreal bevacizumab for treatment of choroidal neovascularization in pathologic myopia. Retina 2006;26(9):1093-4.

27. Chen E, Park $\mathrm{CH}$. Use of intravitreal bevacizumab as a preoperative adjunct for tractional retinal detachment repair in severe proliferative diabetic retinopathy. Retina 2006;26(6):699-700.

28. Carvounis PE, Kopel AC, Benz MS. Retinal pigment epithelium tears following ranibizumab for exudative age-related macular degeneration. Am J Ophthalmol 2007;143(3):504-5.

29. Bakri SJ, Kitzmann AS. Retinal pigment epithelial tear after intravitreal ranibizumab. Am J Ophthalmol 2007;143(3):505-7.

30. Bressler NM. Photodynamic therapy of subfoveal choroidal neovascularization in age-related macular degeneration with verteporfin: two-year results of 2 randomized clinical trials-tap report 2. Arch Ophthalmol 2001;119(2):198-207. 
31. Barbazetto I, Burdan A, Bressler NM, et al. Photodynamic therapy of subfoveal choroidal neovascularization with verteporfin: fluorescein angiographic guidelines for evaluation and treatment--TAP and VIP report No. 2. Arch Ophthalmol 2003;121(9):1253-68.

32. Pece A, Isola V, Vadala M, Calori G. Photodynamic therapy with verteporfin for choroidal neovascularization associated with retinal pigment epithelial detachment in age-related macular degeneration. Retina 2007;27(3):342-8. 
Figure Legend

Figure 1: a) There is a subfoveal serous choroidal neovascular membrane in case 7 (arrows). b) The FA demonstrates the fibrovascular PED centrally with a surrounding serous PED (arrows). c) Two weeks after her first intravitreal bevacizumab injection, she developed a tear of the RPE that spared the fovea (arrows). d) Repeat FA demonstrates a tear of the RPE that spared the fovea. With subsequent ranibizumab injections, the patient's vision improved to 20/25. 